\title{
An overview of ivabradine
}

\section{Tumelo Ramoleta, Natalie Schellack, ${ }^{*}$ Elmien Bronkhorst}

Sefako Makgatho Health Sciences University

*Corresponding author, email: natalie.schellack@smu.ac.za

\begin{abstract}
This article provides an overview of the therapeutic effects of ivabradine in the treatment of coronary artery disease (CAD), and in the management of stable angina pectoris (SAP) and congestive cardiac failure (CCF). Patients with SAP have a reduced quality of life and are unable to work efficiently, resulting in the increased use of healthcare resources. Unlike the other antianginal drugs (i.e. the beta-blockers, calcium-channel blockers and organic nitrates), ivabradine specifically targets the $I_{f}$ current of the sinus node. It reduces the frequency of angina attacks and increases the time until symptoms during work appear. Clinical evidence has shown that ivabradine is an effective anti-ischaemic and antianginal agent, comparable to the beta-blockers and calcium-channel antagonist in controlling the symptoms of myocardial ischemia.
\end{abstract}

Keywords: ivabradine, $\mathrm{I}_{f}$ current, sinus node, congestive cardiac failure, angina pectoris, antianginal agent

\section{Introduction}

Coronary artery disease (CAD) claims the lives of more than seven million people in the world every year, and most of those are in developing countries. ${ }^{1,2}$ Optimal medical therapy is actively encouraged and includes using the recommended guidelines as part of management. Patients who have had CAD not only have an affliction of reduced quality of life, but also have an increased risk associated with cardiovascular events, like angina pectoris and myocardial infarction (MI). Angina pectoris is a common symptom of CAD; percutaneous coronary intervention $(\mathrm{PCl})$ is frequently used to relieve the symptoms of angina. The combination of ivabradine and a suitable $\beta$-blocker in patients with angina, who had $\mathrm{PCl}$, has proven to be beneficial. ${ }^{1}$

Cardiovascular and all-cause mortality can be associated with resting heart rate, and the mortality benefit of cardiovascular drugs can be linked to their heart rate-lowering effects. ${ }^{3}$ The development of a pure heart rate-lowering drug proved to be of great interest in establishing the benefits of heart rate reduction alone. Ivabradine is the first pure heart rate-lowering agent that successfully completed clinical trials for the treatment of stable angina pectoris. $^{3}$

\section{Congestive cardiac failure}

Chronic heart failure is a serious and disabling condition, affecting $2-3 \%$ of the population. The prognosis of chronic heart failure is fairly poor, and heart rate reduction, especially a reduction in resting heart rate, is particularly important in managing the disease process. ${ }^{4}$
Due to its inability to be detected and the lack of conclusive diagnostic assessments, the clinical diagnosis of congestive heart failure (CHF) is reliant on vigilant physical assessment and the use of diagnostic tests, such as chest radiography and the electrocardiogram (ECG). ${ }^{5}$ Throughout recent years many advances in treatment have been made, but CHF still claims the lives of many. ${ }^{6}$ High mortality and morbidity are seen in patients with $\mathrm{CHF}^{4}$

\section{Angina pectoris}

According to Fihn et al., ${ }^{7}$ angina pectoris is a pain or discomfort in the chest that is due to coronary heart disease that occurs when the heart is deprived of blood. This might be due to blockages or narrowing of the arteries. Although oxygen demand is in close relation to the oxygen consumption of an organ, the two concepts are not the same. Angina pectoris is caused by an imbalance between myocardial perfusion and oxygen demand, causing myocardial ischaemia. ${ }^{8}$

\section{Oxygen demand and risk markers}

Certain body organs'actions are directly related to their respective demand for oxygen; thus, the higher the oxidative state of an organ (like the heart), the higher the oxygen demand will be. ${ }^{9}$ The major known risk markers for CAD are total cholesterol, systolic and diastolic blood pressure, smoking and diabetes. Less predictive risk markers include obesity, physical inactivity and a positive family history. Recently, metabolic syndrome and resting heart rate have been acknowledged as risk markers. ${ }^{10}$ Heart rate is a major determinant of myocardial oxygen use; thus, 
if increased, it is accountable for the majority of cardiovascular episodes in congestive cardiac failure (CCF). ${ }^{11}$ According to the latest South African Medicines Formulary (2016), ${ }^{12}$ ivabradine, an $I_{f}$ ion channel inhibitor, is indicated as monotherapy in the treatment of chronic stable angina and stable chronic heart failure, or in combination with suitable beta-blockers.

Myocardial oxygen consumption $\left(\mathrm{MVO}_{2}\right)$ is the oxygen requirement of the heart muscle or myocardium (refer to Table 1 ). By way of comparison, Table 2 provides the $\mathrm{MVO}_{2}$ of other organs in the body. ${ }^{9}$

Table l: $\mathrm{MVO}_{2}$ requirements of the heart during different conditions ${ }^{9}$

\begin{tabular}{|c|c|}
\hline Cardiac State & $\begin{array}{c}\mathrm{MVO}_{2} \\
(\mathrm{ml} \mathrm{O} / \mathrm{min} \text { per } 100 \mathrm{~g})\end{array}$ \\
\hline Arrested heart & 2 \\
\hline Resting heart rate & 8 \\
\hline Heavy exercise & 70 \\
\hline
\end{tabular}

Table Il: Oxygen consumption by organs in the human body, measured in $\mathrm{ml} \mathrm{O}_{2} /$ min per $100 \mathrm{~g}^{9}$

\begin{tabular}{lc}
\hline Organ & $\begin{array}{c}\mathbf{O}_{2} \text { Consumption } \\
\left(\mathbf{m l ~} \mathbf{~}_{2} / \mathbf{m i n} \text { per } \mathbf{1 0 0} \mathbf{~ g}\right)\end{array}$ \\
\hline Brain & 3 \\
Kidney & 5 \\
Skin & 0.2 \\
Resting muscle & 1 \\
Contracting muscle & 50 \\
\hline
\end{tabular}

An increasing heart rate increases myocardial oxygen demand, reduces ventricular efficiency and relaxation, and decreases myocardial perfusion by shortening the duration of diastole, thus inducing myocardial ischaemia and subsequent angina. ${ }^{11,13}$ Raised heart rate is also associated with vascular oxidative stress, endothelial dysfunction and the acceleration of atherogenesis. ${ }^{13}$ An increased heart rate induces restriction of blood supply to tissues, leading to a shortage of oxygen because it increases oxygen demand and therefore reduces myocardial perfusion.

\section{Ivabradine}

Unlike the other treatment options for CHF, ivabradine uses a different mechanism of action. Ivabradine is a selective inhibitor of the $I_{f}$ ion channel found in the cardiac pacemaker cells of the Sinoatrial node (SA). Cardiac pacemaker cells generate the spontaneous slow diastolic depolarisation that drives the membrane voltage away from a hyperpolarised level towards the threshold level for initiating a subsequent action potential. This will generate the rhythmic action potentials that spread through the heart and trigger myocardial contraction. ${ }^{3}$ Ivabradine specifically blocks cardiac pacemaker cell $f$-channels and exerts significant inhibition of this current at concentrations that do not affect other cardiac ionic currents. ${ }^{3}$ Myocardial contractility and atrioventricular conduction are maintained while heart rate at rest and during exercise is reduced. ${ }^{13}$
The $\mathrm{I}_{f}$ current is a mixed $\mathrm{Na}^{+}-\mathrm{K}^{+}$-inward ionic current activated by hyperpolarisation, which determines the slope of the diastolic depolarisation, and in turn controls the rate of heart beat. It is one of the most important ionic currents for regulating pacemaker activity in the sinoatrial (SA) node. ${ }^{11}$ Ivabradine is the first specific heart rate-lowering agent to have completed clinical development for stable angina pectoris.

Ivabradine is an effective antianginal and anti-ischemic drug, not inferior to the $\beta$-blocker, atenolol, and the calcium-channel antagonist (CCA), amlodipine. ${ }^{14}$ It reduces the frequency of angina attacks and increases the time until symptoms of angina during exercise begin to show. Ivabradine is not associated with the typical adverse reactions associated with the $\beta$-blockers or other antianginal drugs, because of its exclusive chronotropic effect (i.e. change in heart rate). ${ }^{14}$ In addition, it is indicated to reduce the risk of hospitalization for worsening heart failure in patients with stable, symptomatic, chronic heart failure with left ventricular ejection fractions $\leq 35 \%$, that are in sinus rhythm with a resting heart rate $\geq 70$ beats per minute, and are either on maximally tolerated doses of $\beta$-blockers or have a contraindication to $\beta$-blocker use.

Ivabradine is indicated in patients that do not respond optimally to therapy previously indicated as antianginal monotherapy or even combination therapy. Ivabradine has also proved to be superior in the reduction of rate-pressure, which is a surrogate marker of myocardial oxygen consumption, as well as of comparable efficacy to amlodipine in improving exercise tolerance. $^{15}$

\section{Current available therapeutic options for CHF}

Current medical therapies to reduce the symptoms of angina pectoris aim to improve oxygen supply and reduce oxygen demand in the myocardium. ${ }^{15}$ Beta-blockers competitively bind to and inhibit $\beta$-adrenoceptors. This reduces myocardial oxygen demand, thus lowering blood pressure, heart rate and contraction of the myocardium. ${ }^{12}$

The slowing of the heart rate (bradycardia) prolongs the relaxation state of the heart, which is the diastole, and this will increase optimal coronary blood flow. ${ }^{16}$ Patients are advised to monitor their body weight, limit salt intake and regularly exercise. The standard pharmacological interventions are indicated in Table III.

\section{The SHIfT trial}

In 2010, the SHIfT trial (Systolic Heart failure treatment with the $\mathrm{I}_{f}$ inhibitor ivabradine Trial) evaluating heart rate reduction through the direct sinus node inhibition was conducted. SHIfT was a multinational, parallel-group clinical trial in patients with moderate-to-severe heart failure and left-ventricular systolic dysfunction. ${ }^{4}$ It was the first study conducted to assess whether heart rate reduction by direct sinus node inhibition can decrease cardiovascular outcomes in patients with chronic heart failure and left ventricular systolic dysfunction. ${ }^{13}$ It was found that ivabradine substantially reduced major risks associated with heart failure when combined with guidelinebased treatment. ${ }^{4}$ 
Table III: Pharmacological management of congestive cardiac failure according to the South African Standard Treatment Guidelines and Essential Medicine List, $2012^{17}$

\begin{tabular}{|c|c|c|}
\hline \multirow[t]{2}{*}{ Medicine } & & Dose and frequency \\
\hline & Hydrocortisone & Oral 25-50 mg daily \\
\hline \multirow[t]{2}{*}{ Diuretic } & Furosemide & Oral $40 \mathrm{mg}$ daily, increased in renal failure \\
\hline & Spironolactone & Oral 25 mg daily \\
\hline ACE-inhibitor & Enalapril & Oral $2.5 \mathrm{mg} 12$ hourly, up to $10 \mathrm{mg} 12$ hourly \\
\hline Beta-blockers & Carvedilol & $\begin{array}{l}\text { Oral } 3.125 \mathrm{mg} \text { daily } \\
\text { Increase after } 2 \text { weeks to } 3.125 \mathrm{mg} 12 \text {-hourly } \\
\text { Increase at } 2 \text {-weekly intervals by doubling the dosage until it is tolerated } \\
\text { at } 25 \mathrm{mg}\end{array}$ \\
\hline Cardiac glycoside & Digoxin & Oral 0.125 mg daily \\
\hline \multirow{2}{*}{ Anticoagulants } & Heparin & Unfractionated SC 5000 units 8 hourly \\
\hline & Warfarin & Oral 5 mg daily \\
\hline Thiamine & & Oral or IM 100 mg daily \\
\hline
\end{tabular}

Figure 1: Treatment of Stable Angina Pectoris according to the Standard Treatment Guidelines/Essential Medicines List (STG/EML) ${ }^{17}$

\section{Oral soluble aspirin $150 \mathrm{mg}$ daily} $+$

Short-acting nitrate - Isosorbide dinitrate SL $5 \mathrm{mg}$ If required, repeat at 5-minute intervals for 3-4 dosages

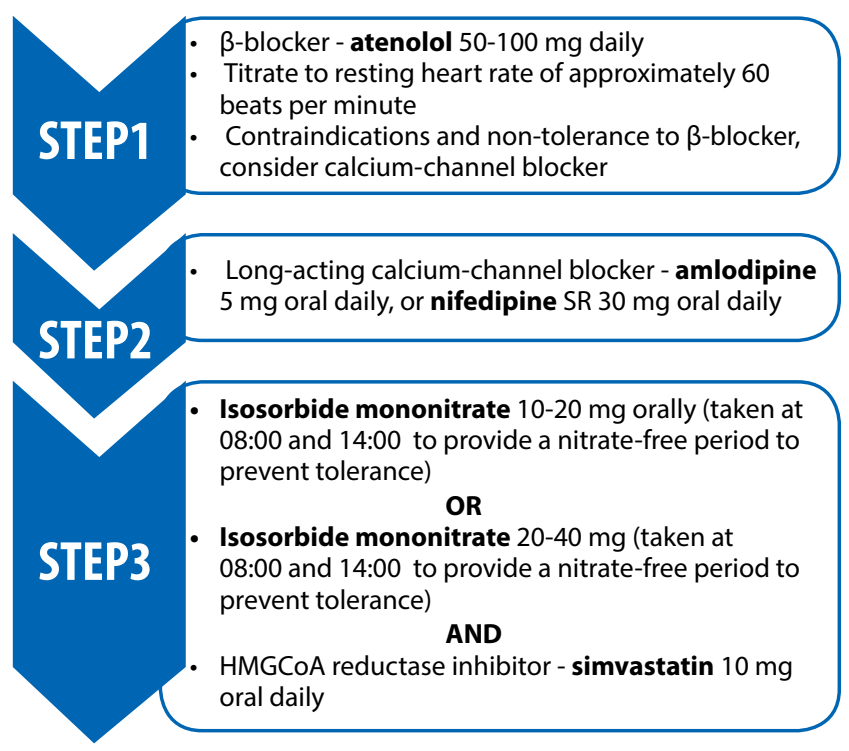

The importance of heart rate in the pathophysiology and clinical course of heart failure was confirmed by the SHIfT study. Ivabradine's beneficial effects of heart rate lowering have therefore been demonstrated with the SHIfT study.

\section{Conclusion}

Strong evidence suggests that heart rate is a marker of risk for cardiovascular disease in the general population, leading to the fact that intervention to reduce elevated heart rate translates into clinical benefit. Some of the groups of drugs used in the treatment of stable angina pectoris, including the $\beta$-blockers and some calcium-channel antagonists, remain the first line of treatment for reducing heart rate, although their use may be limited by their contraindications and adverse reactions. If a patient is unable to tolerate a $\beta$-blockers, ivabradine is likely to be of benefit.

Heart rate is determined by spontaneous electrical pacemaker activity in the sinoatrial node, controlled by the $\mathrm{I}_{f}$ current. Ivabradine is the first specific heart rate lowering agent that has completed clinical development for stable angina pectoris. It is selective for the $\mathrm{I}_{f}$ current, lowering heart rate at concentrations that do not affect other cardiac ionic currents. Specific heart rate and cardiac failure risk lowering with ivabradine reduces myocardial oxygen demand, simultaneously improving oxygen supply. Ivabradine has no negative inotropic or lusitropic effects, preserving ventricular contractility, and does not change any major electrophysiological parameters that are not related to heart rate. Randomised clinical studies in patients with congestive cardiac failure have shown that ivabradine effectively reduces heart rate, improves exercise capacity and reduces the number of angina attacks. Ivabradine therefore offers a valuable approach to lowering heart rate exclusively.

\section{References}

1. Werdan K, Ebelt H, Nuding S, Hopfner F, Stockl G, Muller-Werdan U. Ivabradine in combination with beta-blockers in patients with chronic stable angina after percutaneous coronary intervention. Adv Ther. 2015. 32:120-137. doi: 10.1093/ eurheartj/ehi586

2. World Health Organization. Types of cardiovascular diseases. 2014 [cited 02 February 2016]. Available from: http://www.who.int/cardiovascular_diseases/en/ cvd_atlas_01_types.pdf

3. Di Francesco C, Camm JA. Heart rate lowering by specific and selective $\mathrm{I}_{f}$ current inhibition with Ivabradine. A new therapeutic perspective in cardiovascular disease. DRUGS. 2004;64(16):1757-65.

4. Swedberg K, Komajda M, Bohm M, Borer JS, Ford I, Dubost-Brama A, et al. Ivabradine and outcomes in chronic heart failure (SHIFT): a randomised placebo-controlled study. Lancet. 2010;376:875-85. doi: 10.1016/ S0140-6736(10)61198-1

5. Figueroa MS, Peters Jl. Congestive Heart Failure: Diagnosis, Pathophysiology, Therapy, and Implications for Respiratory Care. Respir Care. 2006;51(4).

6. Nadar S, Prasad N, Taylor RS, Lip GY. Positive pressure ventilation in the management of acute and chronic cardiac failure: a systematic review and meta-analysis. Int J Cardiol. 2005;18(2):171-85. doi: 10.1016/j.ijcard.2004.03.047

7. Fihn SD, Gardin JM, Abrams J, et al. Guideline for the diagnosis and management of patients with stable ischemic heart disease: a report of the American 
College of Cardiology Foundation. JACC. 2012;126(25):354-471. doi: 10.1161/ CIR.0b013e318277d6a0

8. Tardif JC, Ponikowski P, Kahan T. Efficacy of the $\mathrm{I}_{f}$ current inhibitor Ivabradine in patients with chronic stable angina receiving beta-blocker therapy: a 4-month, randomized, placebo-controlled trial. Eur Heart J. 2009;30:540-8. doi: 10.1093/ eurheartj/ehn571

9. Klabunde RE. Cardiovascular Physiology Concepts. 2nd ed. Lippincott Williams \& Wilkins; 2011.

10. Borer JS. Heart rate: from risk marker to risk factor. Eur Heart J. 2008;10 Suppl F: F2-F6. doi:10.1093/eurheartj/sun019

11. Tardif JC, Ford I, Tendera M, et al. Efficacy of Ivabradine, a new selective $I_{f}$ inhibitor, compared with atenolol in patients with chronic stable angina. Eur Heart J. 2005;26:2529-36. doi: 10.1093/eurheartj/ehi586

12. Rossiter D, Blockman M. South African Medicines Formulary. 12th ed. Cape Town: Health and Medical Publishing Group of the South African Medical Association; 2016.
13. Cowie MR. Ivabradine: The start of a SHIFT in heart failure treatment. Interv Cardiol. 2013;5(1):415-26.

14. Marquis-Gravel G, Tardif J. Ivabradine: the evidence of its therapeutic impact in angina. Core Evid. 2008;3(1)1:1-12. doi: 10.3355/ce.2008.008

15. Ruzyllo W, Tendera M, Fox KM. Antianginal efficacy and safety of Ivabradine compared with amlodipine in patients with stable effort angina pectoris: a 3 month randomised double-blind, multicentre, non-inferiority trial. PubMed. 2007;67(3):393-405.

16. Sulfi S, Timmis AD. Ivabradine - the first selective sinus node $I_{f}$ channel inhibitor in the treatment of stable angina. Int J Clin Pract. 2006;60(2):222-8. doi: 10.1111/j.1742-1241.2006.00817.x

17. National Department of Health (NDoH). Standard Treatment Guidelines/ Essential Medicine List (STG/ EML); 2013. 